\title{
Precocious Utilisation at Reproduction of Female Youth Sheep from Țigaie Breed
}

\author{
Constantin PASCAL ${ }^{1, *}$, Traian ȘTEFAN ATANASIU ${ }^{3}$, Ionică NECHIFOR ${ }^{1,3}$, Costică CRISTIAN $^{2}$ \\ ${ }^{1}$ University of Agricultural Sciences and Veterinary Medicine Faculty of Animal Science Iasi-Romania \\ ${ }^{2}$ Agricultural Station of Research and Development for Sheep and Goat Growing Secuieni - Bacău \\ ${ }^{3}$ Agricultural Station of Research and Development for Sheep and Goat Growing Popăuți - Botoșani \\ * corresponding author: pascalc61@yahoo.com; pascalc@uaiasi.ro
}

Bulletin UASVM Animal Science and Biotechnologies 73(2)/ 2016

Print ISSN 1843-5262; Electronic ISSN 1843-536X

DOI:10.15835/buasvmcn-asb: 12255

\begin{abstract}
Ovine rearing represents a domain being in a full development process in Romania. At the base of this tendency are the solicitation of local and external markets for basic production, respectively meat and milk. To record favourable economical results farmers wants to apply the most optimal technologies so, economical efficiency to reach a maximum level for each female which is part of the livestock (Pascal, 2015, Daraban, 2006). One of those technologies refers also at precocious utilisation at reproduction of a female youth. So, the aim of effectuated research was represented by studying of possibilities for utilization at reproduction of female youth at an age still from the first year of life.Biologic material was represented by domestic ovine, from Țigaie breed, reared in different farms situated in the North-East part of Romania. Experimental batches were formed by females with different ages, but all of them being utilized for the first time at mating. Respecting those demands were formed three batches differentially by age between them, which had, at the moment of utilization for reproduction, 9 months (L1), 18 months (L2) and 22 months (L3). Control batch was formed by adult females belonging to the same breed (LM). In the current research were tracked more aspects, the most important being the ones in which were analyzed the influence of sheep' age on specific indexes of reproduction function, on the total duration of gestation and on further corporal development of youth females. The obtained data were statistically processed using ANOVA software, and for determination of differences and their signification were utilized Fisher and Tukey tests. The obtained results allow us to enlightened the fact that even, in case of batches formed by female youth, the mean values for studied parameters were very close to the ones specific to adult sheep, differences are significant in majority of situations for $\mathrm{p}>0.01$.
\end{abstract}

Keywords: Tigaie sheep, reproduction indexes, precocity

\section{INTRODUCTION}

The main measure, as it should be taken to increase the profitability of sheep breeding, is the increase in the number of lambs which resulted from each female of the base group, achievable through the application of reproductive technologies of intensive type, implicitly by early use of young female sheep for reproduction.

To use as early as possible the youth female for breeding, without affecting the body's development, a particular attention will be paid to increasing the technology applied to young categories (Pascal et al., 2000). By proceeding in this way, females have a higher intensity of growth and puberty will install earlier. By giving to this task a constant and permanent character, gradually the population may change, becoming even more precocious. Puberty represents the moment when the reproduction is possible for the 
first time and is based on the accomplishment of the following conditions:

- ovulation to be present;

- ovum to be fecundated;

- the product of conception must led to the term.

In terms of optimum age and weight for usage for the first time at the mount of youth sheep, there is a wide variation between breeds. So, as age, as a result of complex Dyrmundson and Haresing research, quoted by Sandu (1993), the age 6-8 months specific for most breeds, but may be delayed for up to 18 months, but mentions other situations in which some young female sheep, from late calving, can conceive as early as the first autumn, meaning at an age older than 4 months.

In terms of live weight indicated for use in breeding for the first time, the literature indicates that reproduction can happen without future negative repercussions when a body development of at least $60-70 \%$ is reached, from the one specific to the adult Merinos sheep, and $50-60 \%$ at the prolific breeds and at the English meat breeds. Females originating from twin calving tend to reach puberty at a young age and at a lower body weight.

\section{MATERIALS AND METHODS}

Biological material was represented by Țigaie sheep, breed at SCDCOC Secuieni-Bacău. The experimental batch use in covering was divided into three groups differentiated by age. Thus, at the date of mating, females from batch 1 (L1) had 9 months, those in batch 2 (L2) had 17 months, and those in the third (L3) experimental batch had the age of 21 months. The control batch was composed of adult sheep older than three years belonging to the same breed (LM).

For the purpose of obtaining coverings and grouped calving, for 30 days in advance of breeding have been practiced stimulant feedings, being given in this sense, at discretion, green meals and approx. $0.3 \mathrm{~kg}$ concentrates per day/head. Mount has been carried out in the range 20-30 September 2013 and for detecting sheep females in heat were used trying rams, and youth weaning was made at 60 days of age.

During the carried out investigations, many aspects have been pursued, among which the most important were represented by the influence of age on the sheep breeding function, total duration of gestation depending on the type of calving, corporal development of sheep according to age.

The data collected were centralized and processed using the ANOVA statistical program, and to determine the differences and their significance, the Fisher and Tukey test has been used.

\section{RESULTS AND DISCUSIONS}

Regarding all batches, the fecundity recorded maximum values, meaning that each calved female has produced at least one lamb. The high value of this index is also a consequence of the very good maintenance condition applied to the four female batches.

Analyzing the dates present in table 1 we can find the apparition of some differentiations between the average values calculated for other specific indices of reproductive function. Thus, the determination of the fertility indices indicates lower values for L1, intermediary (87\%) for batches where the age at breeding was 17 and 21 months respectively, and higher (85\%) for females that formed the L2. This indicator is important in the analysis of the function of reproduction because it is based on the reporting of the number of live products obtained from females of a certain age (or age group) at the average number of females of the age.

The indicator of fertility has an upward curve for the experimental groups, and from the data obtained it is found that it is influenced in expression also by the age of the animals. At the group represented by females, which at the time of mating had 9 months, the value of the index was $108 \%$, increased at $112 \%$ for the group L2, reaching the value of $113 \%$ for L3. In the case of females which formed the control group, the value of this indicator was of $108 \%$.

The birth rate calculated according to the number of lambs obtained (living and dead) in a given period of time related to the number of the total population. Better average value was obtained from the total number of sheep which formed the control group. On the whole, all of these data differ from those resulted through the application of the system of reproduction based on artificial seeding (Pascal et al. 1998).

Age of sheep and body development. The degree of bodily development of females from the 
Tab. 1. The main indices of breeding (\%)

\begin{tabular}{ccccc}
\hline Specification & L1 & L2 & L3 & LM \\
\hline Fecundity & 100 & 100 & 100 & 100 \\
\hline Fertility & 87 & 85 & 88 & 96 \\
\hline Prolificacy & 108 & 112 & 113 & 108 \\
\hline Natality & 86 & 91 & 97 & 113 \\
\hline
\end{tabular}

Tab. 2. The age and weight of females at mating and calving

\begin{tabular}{|c|c|c|c|c|c|}
\hline \multirow{2}{*}{ Batch } & \multirow{2}{*}{ Statistics } & \multicolumn{2}{|c|}{ The age of sheep (days) } & \multicolumn{2}{|c|}{ Corporal weight (kg) } \\
\hline & & At mating & At calving & At mating & At calving \\
\hline \multirow{5}{*}{ L1 } & $\bar{x} \pm s_{\bar{x}}$ & $289.22 \pm 1.841$ & $437.00 \pm 9.224$ & $41.62 \pm 0.79$ & $48.850 \pm 0.513$ \\
\hline & $s^{x}$ & 9.376 & 33.562 & 2.568 & 2.618 \\
\hline & V\% & 3.893 & 14.562 & 6.105 & 5.360 \\
\hline & minimum & 264 & 411 & 38 & 45 \\
\hline & maximum & 309 & 463 & 47 & 56 \\
\hline \multirow{5}{*}{ L2 } & $\bar{x} \pm s$ & $517.212 \pm 1.631$ & $666.901 \pm 2.533$ & $45.300 \pm 0.505$ & $51.110 \pm 0.470$ \\
\hline & $\mathrm{s}^{\bar{x}}$ & 9.199 & 24.211 & 3.222 & 3.221 \\
\hline & V\% & 7.710 & 7.081 & 6.886 & 5.456 \\
\hline & minimum & 478 & 624 & 45 & 53 \\
\hline & maximum & 537 & 693 & 53 & 61 \\
\hline \multirow{5}{*}{ L3 } & $\bar{x} \pm s$ & $639.055 \pm 3.822$ & $789.810 \pm 8.543$ & $47.611 \pm 0.612$ & $52.020 \pm 0.6021$ \\
\hline & $s^{x}$ & 11.371 & 44.747 & 2.704 & 2.635 \\
\hline & V\% & 9.308 & 6.057 & 5.342 & 4.391 \\
\hline & minimum & 578 & 729 & 48 & 57 \\
\hline & maximum & 645 & 801 & 57 & 66 \\
\hline \multirow{5}{*}{ LM } & $\bar{x} \pm s_{\bar{v}}$ & $1303.66 \pm 9.283$ & $1451.220 \pm 5.281$ & $54.020 \pm 0.020$ & $59.011 \pm 0.214$ \\
\hline & $\mathrm{s}^{x}$ & 11.652 & 43.652 & 2.630 & 3.029 \\
\hline & $\mathrm{V} \%$ & 9.951 & 11.959 & 5.186 & 5.223 \\
\hline & minimum & 1061 & 1205 & 49 & 56 \\
\hline & maximum & 1384 & 1537 & 62 & 68 \\
\hline
\end{tabular}

four lots was done through analysis of body weight, determined at the date and at the time of mating and parturition, data being presented in table 2. For a real analysis of the actual level of bodily development were made body measurements, carried out immediately after the calving (table 3 ).

At the time of mating, for the experimental lots L1, L2 and L3, the mean body weight was over $75 \%$ of that specific adult sheep (LM), thereby fulfilling the requirements for use in breeding. In terms of the breeding weight there were found differences between the batches, but they were significant only for $\mathrm{p}>0.01$ between L1 and L4;
L3 and L1; L2 and L1. The differences recorded for age at breeding and calving at were very significant among all batches for $\mathrm{p}>0.01$.

Analyzing the batch where the females had the smallest average age at the date of mating, namely $289.22 \pm 1.841$ days, they had a body weight of $41.62 \pm 0.79 \mathrm{~kg}$ which represented $75.9 \%$ from the weight at the time of the mating of the mother sheep from the control group. The age at the date of parturition has been influenced by the average length of gestation, aspect evidenced in other researches carried out on other breeds (Petcu et. al 1997). 
Tab. 3. Body dimensions (cm)

\begin{tabular}{|c|c|c|c|c|c|c|c|c|}
\hline \multirow{3}{*}{ Specification } & \multicolumn{8}{|c|}{ The studied batches } \\
\hline & \multicolumn{2}{|l|}{ L 1} & \multicolumn{2}{|l|}{ L 2} & \multicolumn{2}{|l|}{ L 3} & \multicolumn{2}{|l|}{ LM } \\
\hline & $\bar{x} \pm s$ & V\% & $\bar{x} \pm s$ & V\% & $\overline{\mathrm{X}} \pm \mathrm{s}$ & V\% & $\bar{x} \pm \mathrm{s}$ & V\% \\
\hline Height at the withers & $66.0 \pm 0.198$ & 9.24 & $67.94 \pm 0.43$ & 3.61 & $69.02 \pm 0.20$ & 7.69 & $69.59 \pm 0.24$ & 5.11 \\
\hline Height at shoulder & $67.72 \pm 0.31$ & 5.9 & $69.81 \pm 0.27$ & 7.41 & $70.04 \pm 0.20$ & 8.25 & $70.22 \pm 0.87$ & 4.54 \\
\hline Torso length & $66.56 \pm 0.40$ & 8.08 & $67.96 \pm 0.16$ & 8.85 & $71.07 \pm 056$ & 10.7 & $72.04 \pm 0.25$ & 8.26 \\
\hline Chest depth & $32.50 \pm 0.37$ & 4.87 & $33.31 \pm 0.14$ & 8.71 & $34.28 \pm 0.15$ & 9.45 & $36.03 \pm 0.23$ & 4.22 \\
\hline Chest perimeter & $97.06 \pm 0.31$ & 7.88 & $98.03 \pm 0.18$ & 7.03 & $98.99 \pm 0.21$ & 8.24 & $99.97 \pm 0.61$ & 7.8 \\
\hline $\begin{array}{l}\text { Perimeter of the } \\
\text { whistle }\end{array}$ & $10.56 \pm 0.12$ & 5.42 & $11.08 \pm 0.52$ & 8.49 & $12.15 \pm 0.55$ & 8.36 & $12.78 \pm 0.21$ & 5.72 \\
\hline
\end{tabular}

Together with other observations, it has been studied the evolution of other indicators resulting from biometric measurements at the sheep from the four batches, differentiated among themselves by age at breeding.

The results obtained allow to clarify that although, in the case of the batches composed of female youth, the average values of the studied parameters are very close to those of adult sheep, the specific differences are significant in most situations for $p>0.01$. Exceptions are the differences found between the height at the withers and torso length between L3 and L2 and thoracic perimeter of L4 and L3 which were significant for $\mathrm{p}>0.05$.

Duration of gestation. Research regarding the duration of gestation was analysed by watching the average total for each of the four lots and then separately for the sheep which have lambed products different as sex and those who had more twins (table 4).

Analyzing the data obtained may find that, in all three experimental batches consisting of young females, compared to the control group, the total duration of pregnancy was more tenuous, where it can be concluded that age constitutes a main factor of influence of gestation, which is supported by other research carried out in this field (Pascal et al. 1987, Pascal et al. 2006b, Niga et al.1987). The differences between the batches were insignificant, except that between the average total gestation of L4 and L2 lots which was significant for $\mathrm{p}>0.05$.

The largest value of the average duration of gestation, if its analysis according to sex of the product, was found to be at sheep that produced males. The same finding is also valid for the analysis of the total length of gestation depending on the number of products produced. Thus, the sheep with more twins, the average duration of gestation was higher compared to that recorded in the case of sheep that produced only one lamb.

These results further support us to affirm also that the sex of offspring and their number shall constitute factors of influence of the total period of parturition.

\section{Acknowledgements}

The performed researches are part of the Sectorial Plan, project code 5.1.9., financed by the Ministry of Agriculture and Rural Development Bucharest-Romania.

\section{CONCLUSION}

1. Application of appropriate technologies for the increase of youth (youth stocks) creates a friendly environment for an early use of youth sheep in breeding.

2. Although, in relation to the age at mating, the indices specific to the breeding function registers superior values at adult sheep, early use of female youth in the case may represent a viable solution to increase the yields.

3 . At the time of the mating there were found differences between the weight of the lots, but they were significant for only $p>0.01$ between $\mathrm{L} 1$ and L4; L3 and L1; L2 and L1.

4. The differences recorded for age at breeding and calving were very significant among all batches for $\mathrm{p}>0.01$.

5. Because for the three experimental batches consisting of young females, compared to the 
Table 4. The duration of gestation in sheep

\begin{tabular}{|c|c|c|c|c|c|}
\hline \multirow[b]{2}{*}{ Batch } & \multirow[b]{2}{*}{ Statistics } & \multicolumn{4}{|c|}{ The total duration of gestation (days) } \\
\hline & & Total & $\begin{array}{c}\text { At sheep which have } \\
\text { lambed males }\end{array}$ & $\begin{array}{c}\text { At sheep which have } \\
\text { lambed females }\end{array}$ & $\begin{array}{c}\text { At sheep which have } \\
\text { lambed twins }\end{array}$ \\
\hline \multirow{5}{*}{ L1 } & $\bar{x} \pm s$ & $148.330 \pm 441$ & $149.555 \pm 0.111$ & $147.931 \pm 0.310$ & $151.002 \pm 0.232$ \\
\hline & $s^{\bar{x}}$ & 0.287 & 0.562 & 0.544 & 0.524 \\
\hline & $\mathrm{V} \%$ & 3.844 & 4.852 & 3.984 & 5.020 \\
\hline & minimum & 141 & 142 & 141 & 144 \\
\hline & maximum & 152 & 144 & 142 & 154 \\
\hline \multirow{5}{*}{$\mathrm{L} 2$} & $\bar{x} \pm s$ & $149.185 \pm 0.485$ & $151.088 \pm 0.051$ & $148.065 \pm 0.654$ & $153.051 \pm 0.144$ \\
\hline & $s^{x}$ & 3.327 & 2.221 & 4.325 & 3.477 \\
\hline & $\mathrm{V} \%$ & 2.230 & 4.581 & 5.021 & 8.808 \\
\hline & minimum & 146 & 147 & 146 & 148 \\
\hline & maximum & 158 & 158 & 158 & 158 \\
\hline \multirow{5}{*}{ L3 } & $\bar{x} \pm s$ & $152.363 \pm 1.063$ & $154.252 \pm 0.085$ & $152.877 \pm 0.913$ & $155.068 \pm 1.012$ \\
\hline & $s^{\bar{x}}$ & 5.514 & 5.025 & 4.611 & 4.581 \\
\hline & $\mathrm{V} \%$ & 3.972 & 4.452 & 4.158 & 6.147 \\
\hline & minimum & 148 & 151 & 147 & 145 \\
\hline & maximum & 158 & 157 & 160 & 158 \\
\hline \multirow{5}{*}{ LM } & $\bar{x} \pm s_{\bar{x}}$ & $154.020 \pm 1.082$ & $155.087 \pm 1.022$ & $152.075 \pm 0.955$ & $155.216 \pm 1.211$ \\
\hline & $s^{x}$ & 5.166 & 8.141 & 5.012 & 5.325 \\
\hline & $\mathrm{V} \%$ & 3.695 & 5.874 & 3.451 & 6.018 \\
\hline & minimum & 145 & 151 & 147 & 149 \\
\hline & maximum & 165 & 159 & 161 & 164 \\
\hline
\end{tabular}

control group, the total duration of pregnancy was more tenuous, one can conclude that age constitutes a main factor of influence of pregnancy.

\section{REFERENCES}

1. Daraban SV, (2006). Technology sheep breeding. Ed Risoprint, Cluj -Napoca, ISBN 973-751-182-4, 978-973751-182-9,

2. Pascal C, Stancescu L, Bosanciuc S (2006a). Researches regardes the precocious utilization in reproduction in the sheep. Scientific Papers, vol. 49, Seria Zootehnie, USAMV Iasi, p 671 - 678. ISSN 1454-7368.

3. Pascal C, Stancescu L (2006b). Precocious reproduction of young sheep of Merinos of Palas breed, Cercetări Agronomice în Moldova, vol 1 (125)., p 67 - 74, ISSN 0379-5837.
4. Niga V, Marin I (1987). Early use for breeding of youth females from the Karakul breed. Scientific papers - ICPCOC Palas - Constanța, vol. II, p 315 -320

5. Petcu D, Șcheiul V, Maltopol Maria, Ionescu Florentina (1987). Research on the length of gestation in sheep with frozen sperm compared with the chilled and gross. Scientific Papers ICPCOC Palas - Constanța, vol. IV, p 287 $-290$

6. Pascal C, Radu, R, Pivodă Carmen Ana (1998). Estimating indices of breeding at artificially inseminated sheep. Scientific Papers, vol. 41/42, p 87-91, Seria ZootehnieUSAMV Iaşi

7. Pascal C, Radu R, Carmen Ana Pivodă (2000). Influence of a permanent stabulation on the growth and develpment of youth sheep from different breeds. Scientific Papers, vol. 43/44, p 64-68, Seria Zootehnie, USAMV Iasi. 